\title{
A Grounded Theory of Collaborative Synchronizing in Relation to Challenging Students
}

Robert Thornberg

\section{Linköping University Post Print}

\section{Tweet}

N.B.: When citing this work, cite the original article.

Original Publication:

Robert Thornberg, A Grounded Theory of Collaborative Synchronizing in Relation to Challenging Students, 2012, Urban education (Beverly Hills, Calif.), (47), 1, 312-342.

http://dx.doi.org/10.1177/0042085911427735

Copyright: SAGE Publications (UK and US) http://www.uk.sagepub.com/home.nav 


\title{
A Grounded Theory of Collaborative Synchronizing in Relation to Challenging Students
}

\author{
Robert Thornberg \\ Department of Behavioural Sciences and Learning, Linköping University, Linköping, Sweden
}

\begin{abstract}
The aim of this study was to investigate multiprofessional collaboration as well as collaboration between professionals and challenging students and their parents in which the focus for these collaborations was on handling the challenging students' academic and social behavior. A grounded theory study of collaboration between a prereferral resource team and teachers, principals, challenging students, and their parents was conducted. Qualitative interview and focus group methods were used. The findings presented a grounded theory of collaborative synchronizing in relation to challenging students around two ideal types, human resource synchronizing and human resource desynchronizing.
\end{abstract}

Keywords: remedial programs, school, school counselors, Sweden

Challenging students are often associated with poor student health and emotional and behavioral disorders and create a lot of problem for teachers and schools. Kaiser and Rasminsky (2009) define challenging behavior among students as behavior that interferes with a student's cognitive, social, or emotional development, is harmful to a student, his peers, or adults, and puts a student at high risk for later school failure, social maladjustment, and physical and mental health problems. In contrast to a confined biomedical model as well as an individualpsychological model, as a researcher my understanding of challenging students is in line with socio-ecological and critical sociological perspectives. From a critical sociological view, the school system constructs most of the "challenging students" as a result of taken-for-granted norms and discourses embedded in the politics and institutions of the society. According to Erevelles (2006), how educational personnel approach students with disabilities or severe school problems is mediated by a societal perspective that labels those students as outside the norm. This normalizing practice of schooling occurs "because public education has used the concepts of difference, deviance, and disability synonymously to justify the exclusion of certain student populations” (p. 366). In addition, according to a socio-ecological perspective, children's development, behavior, health, and well-being are a function of complex interactions between biological components, psychological states and processes, as well as the processes and characteristics of the environments in which they function (Gutkin, 2009; Sun \& Stewart, 2007) — “a function of the quality of relationships among individual, family and institutional systems" (Sun \& Stewart, 2007, p. 576). Hence, to conduct effective interventions, practitioners have to take advantage of coordinating and involving the many human resources and competences around the target student, such as teachers, parents, special educators, school psychologists, and so on.

Furthermore, research from other fields has shown that close and well-developed collaboration between individuals from different professions has many advantages as compared to when individuals work, solve problems, and make decisions and interventions on their own, independently, and in isolation from each other (e.g., Bennett-Emslie \& McIntosh, 1995; Cook, Gerrish, \& Clarke, 2001; Poulton \& West, 1999; Toseland, Ivanoff, \& Rose, 1987; Toseland, Palmer-Ganeles, \& Chapman, 1986). Moreover, implementation of multiprofessional school-based health care services has shown to (a) have positive effects on students' academic achievement (Brown \& Bolen, 2008; Shaw, Kelly, Joost, \& Parker-Fisher, 1995), (b) reduce absence from school (Gall, Pagano, Desmond, Perrin, \& Murphy, 2000), and (c) reduce aggressive as well as substance use behaviors among students (see Brown \& Bolen, 2008). Nevertheless, research on multiprofessional teams and collaboration in school settings 
has shown a lot of pitfalls or problems:

- the problems of professional boundaries, mistrust, and professional outgroup devaluation, especially teachers' suspicions, skeptical attitude, or rejection of nonteaching professionals who in turn are aware of this suspicion and potential hostility, and thus avoid engaging with teachers (Robinson, 2002; Spratt, Shucksmith, Philip, \& Watson, 2006);

- teachers who feel threatened when encouraged to question their own practice and to try working in other ways (Farrell, Howes, Jimerson, \& Davies, 2009);

- nonteaching professionals are not comfortable with offering consultation to teachers regarding issues of classroom practice (Robinson, 2002);

- insufficient teacher involvement or participation in the process and lack of respect for teachers by some nonteaching workers (Meyers, Valentino, Meyers, Boretti, \& Brent, 1996; Robinson, 2002; Slonski-Fowler \& Truscott, 2004);

- teachers generally cited lack of time and scheduling difficulties as reasons for their inability to become involved (Robinson, 2002);

- low degree of treatment integrity in how teachers cope with team-recommended interventions (Kovaleski, Gickling, Morrow \& Noell, 1996); and

- weak or insufficient parent involvement and participation in the process as well as lack of respect for parents (Klingner \& Harry, 2006).

Hence further research on multiprofessional collaboration and meaning-makings of actors involved in such processes is urgent to better understand and cope with pitfalls and problems that tend to occur or develop in the process. The aim of this study is to investigate multiprofessional collaboration as well as collaboration between professionals and challenging students and their parents in which the focus for these collaborations is on handling the challenging students' academic and social behavior. The analysis resulted in a grounded theory of collaborative synchronizing of human resources in relation to challenging students.

\section{Method}

I used qualitative methods, guided by a grounded theory approach (Charmaz, 2006, 2008, 2009; Glaser, 1978, 1998; Glaser \& Strauss, 1967), to investigate the processes and sensemakings of collaboration between different professionals (teachers, principals, and resource team members), parents, and challenging students. According to Meyers, Truscott, Meyers, Varjas, and Smith Collins (2008), qualitative research is appropriate for studying the process variables in the context of particular settings. It offers the opportunity to develop a deeper understanding of participants' perspectives. "Qualitative methods facilitate study of issues of depth and detail” (Patton, 2002, p. 14), and are capable of discovering important discourses and nuances of social processes and actors' meanings that might be less visible in large-scale studies (Mishna, Saini, \& Solomon, 2009).

\section{Constructivist Position of Grounded Theory}

Constructivist grounded theory approach assumes that neither data nor theories are discovered, but are constructed by the researcher as a result of his or her interactions with the field and its participants (Charmaz, 2006, 2008, 2009). Data are co-constructed by researcher and participants, and colored by the researcher's perspectives, values, privileges, positions, interactions, and geographical locations (Charmaz, 2008, 2009; Mills, Bonner, \& Francis, 2006). Data as well as analysis are "created from shared experiences and relationships with participants and other sources of data” (Charmaz, 2006, p. 130). This position takes a middle ground 
between the realist and postmodernist positions by assuming an "obdurate reality" (cf. Blumer, 1969) at the same time as it assumes a relativist epistemology, multiple realities, and multiple perspectives on these realities (Charmaz, 2008, 2009). Social realities are mutually constructed through interaction and are therefore subject to redefinition, and are somewhat indeterminate. The grounded theory generated in the current study is built on social constructed data - acts of interpretation of participants' meanings and narratives - and it is situated and located in a particular context. In line with the constructivist grounded theory tradition, I have tried to understand the participants' beliefs, purposes, experiences, the actions they take, and reasons for their actions and inactions from their perspectives (Charmaz, 2009), and based on their narratives conceptualized a grounded theory.

\section{Background}

Consultations are common in Swedish schools in which school psychologists, school counselors, or special educators from school-based multiprofessional student-health teams act as consultants and teachers as consultees. Consultation is usually a one-to-one relation or one consultant to a couple of teachers. Team discussions are not recognized as part of the consultation and typically the teachers are not present. The result of the team discussion might be an offer to a teacher to consult with one of the members of the team. Nevertheless, in their problem-solving discussions, student-health teams rarely contextualized the problems as responses to what had happened in the classroom, or as a consequence of the pedagogical arrangements in the class, but mostly focused on the target students' biological and psychological deficiencies (Hjörne \& Säljö, 2004, 2008), which in turn limited the consultation possibilities with teachers (the same problem has been found in qualitative studies investigating American prereferral team processes, for example, Klinger \& Harry, 2006; Knotek, 2003; as an exception, in a Swedish study on preschool consultation, the psychologists were more prone to focus on the teachers’ practices, see Hylander, 2003).

The resource team initiative in the current study was a pilot project. It was set up, funded, and organized by the local government in a medium-sized Swedish town to counteract the prevalent "within-child" explanation trend and instead initiate a more social-ecological model and a social inclusion approach. Hence, external teams-like the resource team-which work toward schools around particular cases of "challenging" or "hard-to-teach" students to analyze the problem with a social-ecological perspective, offer school consultation, promote change of school and classroom contexts (including teachers' practices and interaction patterns with students), and enhance inclusive education, are still rather rare in relation to the Swedish school system. It is significantly more common in Sweden to treat challenging students in line with biomedical and individual-psychological models as well as considering students' families as possible roots of the problem, rather than analyzing how teachers' practices and other contextual factors within the school and the classroom might create or contribute to the problem.

The resource team initiative began in December 2006 in two districts comprising six elementary schools in a medium-sized Swedish town (note that in the Swedish school system, elementary school ranges from kindergarten class to ninth grade). Five of the six schools were involved in the resource team initiative. Whereas three of the schools involved were located in a socially disadvantaged district, the other two were located in a socially mixed district. On average, there were about 250 students in each school (the size ranged from about 170 to 345 students).

The resource team project was designed (a) to provide immediate assistance to challenging students with psychosocial problems and their parents, (b) to employ problem solving and collaborative consultation with teachers, (c) to develop interventions and changes in school that address the needs of the students and their teachers, and thus (d) to help maintain at-risk 
students in the regular classroom and curriculum. During the first period, team building and development were conducted and information about the resource team was distributed to the six schools in the area. During the spring of 2007, the team started to work with specific student cases.

The resource team consisted of four members - two trained social workers and two special educators. The principal in each school could apply for resource team assistance regarding individual student cases. A special committee, organized by the local government, decided which applications the team would work with. The committee was not made up of school professionals but consisted of administrative personnel from the local government. The team handles 6 to 10 students at the same time. They offered them intensive support for a limited time period (normally 6 months, but in some cases the period was extended to 12 months). At the time of conducting the study, the team had completed 15 student cases and was working with additionally 7 student cases that were completed after the study had been conducted. Generally, the cases involved both academic and behavioral problems (e.g., absenteeism, severely disruptive behavior in classroom, aggression, and delinquency). Some of the students had also received an ADHD diagnosis.

In each student case, two team members-one trained social worker and one special educator-worked in cooperation, and one of them (in some cases a social worker, in other cases a special educator) visited the school and interacted with the target student and the teachers for an extended period. The team members began their work on individual cases by acquiring data (classroom observations, conversations with teachers, the student, the parents, and other relevant individuals) for the three first weeks. They also initiated relationship building with the student and his or her parents as well as with the contact teacher. The contact teacher was the class teacher or the mentor of the student and functioned in the specific case as the main contact person between the resource team and the school.

\section{Participants}

In total 30 individuals participated in the study. The participants had one thing in common, namely, that in different ways they all were or had been involved in the resource team project. All four members of the resource team and all the principals from the five schools were included (note that, in Sweden, there could be more than one principal at a school). A voluntary sampling procedure was conducted to recruit teachers, parents, and students to participate in the present study, which resulted in 8 teachers (in this article, "teachers" refer to general education teachers, whereas "special educators" refer to special education teachers), 4 students (3 male students and 1 female student; 15 to 16 years old, in eighth and ninth grades), and 7 parents (4 fathers and 3 mothers) representing 6 of the target students in the resource team project. Since the present study focused on multiprofessional consultation, the analysis is mostly grounded in data derived from the professionals (teachers, team members, and principals) even if data from students and parents have also been used, but more as background sources and complements.

\section{Data Collection}

I conducted four focus groups: (a) a focus group with the principals (53 min), (b) a focus group with 5 teachers ( $1 \mathrm{hr}$ and $24 \mathrm{~min}$ ), (c) a focus group with 3 teachers (38 min), and a focus group with the resource team (1 hr and $31 \mathrm{~min})$. Focus groups are group interviews, in which "a moderator guides the interview while a small group discusses the topics that the interviewer raises” (Morgan, 1998, p. 1). According to Morgan (1998), focus groups are used to generate a rich understanding of participants' experiences and beliefs. Participants do not only interact with the researcher (as in individual interviews) but more so with each other, which gives the researcher the opportunity to learn the participants' own language instead of 
imposing the researcher's language on them, resulting in a greater access to their perspectives and conceptual worlds (Wilkinson, 1999). Based on ethical considerations regarding the students and parents in the study (i.e., focus groups would put them in a position of talking about very personally sensitive issues in front of other participants), I chose individual qualitative interviews instead of focus groups. The individual interviews with the students ranged in duration from 13 to $21 \mathrm{~min}(M=16 \mathrm{~min})$. Five parent interviews were held individually (3 fathers and 2 mothers). The sixth parent interview included a parent couple, that is, a mother and a father of the same child. The parent interviews ranged in duration from 16 to $44 \mathrm{~min}$ ( $M$ = $33 \mathrm{~min}$ ). Qualitative interviews enabled the students and parents the opportunity to present their individual understandings and experiences, and for me as a researcher to follow up their narratives with explorative questions (King \& Horrocks, 2010). All the focus groups and interviews were recorded with a minidisc recorder, and then transformed into MP3 files.

\section{Data Analysis}

Coding and analysis were conducted directly on the audio data (MP3 files) by using NVivo 8. Grounded theory methods, that is, coding, constant comparison, memoing and memo sorting, were used to analyze data (Charmaz, 2006; Glaser, 1978, 1998; Glaser \& Strauss, 1967) based on a constructivist position (e.g., Charmaz, 2006, 2008, 2009). The following main steps were taken: (a) Initial coding in which codes were constructed by comparing data segments and using analytical questions such as "What is this data a study of? What does the data suggest? What happens in the data? From whose point of view? What category does this specific datum indicate?" Initial coding involved naming words, lines, and segments of data. (b) Focused coding in which the most significant and frequent codes from the initial coding were compared to each other to synthesize the large amounts of data. (c) Theoretical coding in which the previously developed codes or concepts were integrated into an analytical story that had coherence.

In line with a constructivist grounded theory approach, I have used and constructed theoretical concepts as interpretive frames that "offer an abstract understanding of relationships" (Charmaz, 2006, p. 140) —and these relationships are not based on observational data on multiprofessional collaboration but on the participants' representations and descriptions of interaction patterns, relationships, and effects. To readers who are unfamiliar with grounded theory research, it is important to recognize that the study was not a quantitative one in which numbers have been investigated. This is a too small sample to make meaningful statistical inferences. The main idea of the study was not to describe numerical tendencies and differences. As a qualitative case study with a grounded theory approach, the main idea was to generate a grounded theory, which is to construct concepts and conceptualize hypothetical relationships between these concepts, grounded in data by grounded theory methods. Furthermore, I have used a broad social psychological framework with a focus on people's representations of social situations (see below) as a starting point, which has given me a loose frame to the interest of this study (cf., Blumer, 1969; Charmaz, 2006).

Consistent with Blumer's (1969) depiction of sensitizing concepts, grounded theorists often begin their studies with certain research inter- ests and a set of general concepts. These concepts give you ideas to pursue and sensitize you to ask particular kinds of questions about your topic. (Charmaz, 2006, p. 16)

Hence, I did not force preconceived ideas and theories directly on data, but used these as "lenses" and tools that helped me to focus the attention on certain phenomena, aspects, and nuances.

\section{The Social Psychological Framework of the Grounded Theory}


People's conceptions or representations of a particular type of social situation influence and guide their perceptions, interpretations, and actions when they are involved in such social situations. An individual does not react and act as a consequence of what another person in the situation says or behaves, but as a consequence of how he or she perceives and interprets the person and his or her actions. How we interpret or define situations, interactions, and other people depends on our representations or conceptions, which we perceive as a taken-forgranted reality that we act on. These statements have a broad scientific social psychological support. Based on research and theory development, this has been claimed by the traditions of social cognition (Fiske \& Taylor, 2007), symbolic interactionism (Blumer, 1969; Charon, 2007), and social representation theory (Deuax \& Philogène, 2001; Moscovici, 2001).

With this broad social psychological perspective in mind, it is reasonable to assume that those social and mental representations that teachers, principals, team members, students, and parents had about themselves and others, about different forms of interactions between one another, about the resource team activity, and about the school and the home, mattered and influenced how they approached, thought about, and behaved in different forms of interactions (e.g., teacher-student interaction, consultations between team members and teachers, school-home communication, interaction between student and team member, and so forth.). To understand their actions and interactions, it is therefore urgent to examine their meanings and representations of the social situations in which they act and interact.

\section{A Grounded Theory of Collaborative Synchronizing}

For the recognized social psychological reasons above and grounded in the analysis of the data, I have constructed a grounded theory of collaborative synchronizing in relation to challenging students in school.

\section{Human Resource Synchronizing}

A core category generated in this study is human resource synchronizing, which refers to processes that included and coordinated different people so that they integrated and interacted together in a way resulting in positive development of the target student. The grounded theory is illustrated in Figure 1. The left side represents phenomena in the interaction between resource team and school that seemed to contribute to human resource desynchronizing, in other words, that counteracted the integrating and coordinating of human resources (teachers, team members, school psychologists, school counselors, social workers, parents, the student him- or herself, and so forth). The right side contains phenomena in the interaction between resource team and school that contributed to synchronizing of human resources.

The concept of human resource has its origin from the area of organizational and management literature in which it refers to the staff that operates an organization (cf., Banfield \& Kay, 2008). In the current analysis, this concept has been used more loosely as a sensitizing concept (Blumer, 1969); in the generated grounded theory, human resource refers to people-professional workers such as teachers and school counselors as well as students and parents.

It is important to emphasize that the two concepts desynchronizing and synchronizing in this grounded theory are two ideal types. Ideal types are hypothetical constructions, which contain fixed reference points that are useful tools to examine, evaluate, and compare real situations. These are not expected to occur in a pure form in real life but should instead be viewed as analytical tools. Synchronizing and desynchronizing are two opposite poles and those interacting processes that took place between resource team individuals and school personnel from the different schools were expressions of intermediate forms in which some were closer to synchronizing, whereas others were closer to desynchronizing. Hence, according to the grounded theory and based on the participants' narratives, the more synchronizing, 
the less desynchronizing, and vice versa. A critical process that appeared to influence the degree of human resource synchronizing was the process of goal setting and negotiation among those who were expected to collaborate.

Figure 1

A Grounded Theory of Collaborative Synchronizing in Relation to Challenging Students

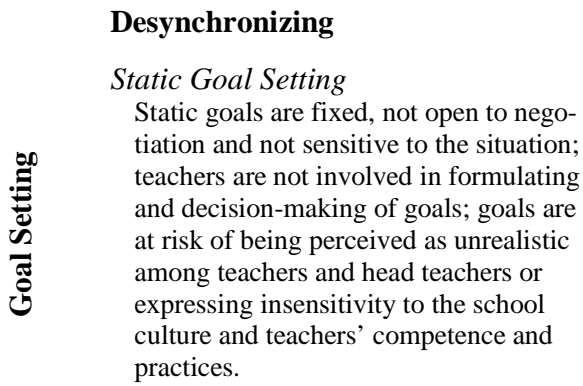

Responsibility Transferring

Relief instead of collaboration; teachers transfer all responsibility to resource team members; resource team members take over the student and work alone; consultation loss; teachers get a diffuse and passive role; delayed interventions; inadequate expectations; strategies for further work after the period of resource team intervention fail to come.

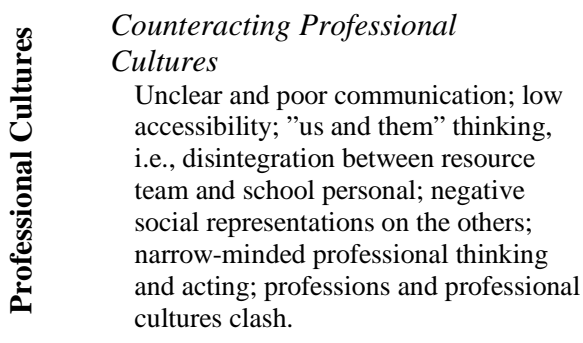

Aversive Relations

Negative attitudes; negative focus; students and parents as antagonists to school personnel; aversive approaches and methods; negative and infective relations; destructive conflict managing.

\author{
Synchronizing \\ Dynamic Goal Setting \\ Dynamic goals have inclusive education \\ as a starting point but are at the same time \\ open to discussion and revision in dialog \\ between all parts; teachers are involved in \\ formulating and decision-making of goals; \\ goals are perceived as realistic among and \\ supported by the school personnel; they are \\ continually evaluated.
}
Responsibility Sharing
The resource team activity is not a one-person job; the work is viewed as a shared project in which everyone takes responsibility and collaborate around the student; teachers have a significant and active role; early interven- tions; adequate expectations; constructive school consultation; strategies for further work after the period of resource team intervention are generated, and a part of this is establishing collaboration between school and home as well as other adequate partners.

\section{Coordinating Professional \\ Cultures \\ Clear and open communication; high accessi- bility; "us” thinking, i.e., high integration between resource team and school personal; see each others as valuable resources; multi- professionalism and a will for mutual under- standing; considering multiple perspectives; professionals and professional cultures are available to everyone to make an active and effective collaboration possible.}

\section{Positive Relations \\ Positive and constructive attitudes; positive focus; students and parents as partners to school personnel; positive approaches and methods; positive and supportive relations; constructive conflict managing.}

\section{Goal Setting}

The conversations with the resource team as well as the teachers and principals indicated that they often had different or conflicting goals, which of course counteracted effective collaboration. This in turn pointed to the important process of goal setting. The analysis shows two types of goal set- ting, static versus dynamic. Static goals easily created desynchronizing because they were not open to negotiation, were not sensitive to the particular situations of different student cases, and did not consider teachers' professional judgments. If they were not gained approval with and supported by the teachers but were instead viewed by them as unrealistic, then there was a high risk that negative expectations among teachers as well as goal conflicts between the teachers and the resource team aroused, and thus resulting in re- 
source desynchronizing. Goal dissonance was indeed a core process in human resource desynchronizing.

Unfortunately, according to teacher and principal reports as well as the attitude expressed in the resource team focus group, static goals were typical in the resource team activity. For example, the official and non-negotiable goal of inclusive education held by team members in every single student case in their approach to the school often collided with what teachers thought and wanted. In many cases teachers often wanted the target students out of their classroom and were skeptical about the very idea of inclusion. "I think that in some way you actually have to listen to the teachers . . . and trust that we actually have some knowledge in this case" (Teacher). The teachers were not against inclusion per se, but were critical because social inclusion seemed to be a "holy cow," and not open for discussion and evaluation. "After all, we have to sit down: 'But what does it look like in this situation? Is this idea really the best?'” (Teacher). Goal dissonance or conflicts between teachers and team members created negative attitudes and expectations among the teachers and counteracted effective collaboration and consultation.

In contrast, dynamic goals were shared, sensitive, open to negotiation, and self-evaluating during the ongoing intervention process and achievements. The starting point and main focus in dynamic goals was on social inclusion (inclusive education), but through systematic data collection, dialog, and continual evaluation, team members, teachers and principals together dis- cussed and judged to what degree inclusive education was reasonable and realistic or if the goals had to be revised.

One important aspect of the goal issue appeared to be a need for revision of the present priority principle of student selection. According to the school staff, the present order of primarily targeting the most acute and severe student cases was problematic because it resulted in unrealistic goals of inclusive education, considering the limits of the resource team intervention period and the resources available.

. . . such incredibly hard cases, which are too difficult. The resource team shouldn't deal with them. Criminal kids. The resource team staff can't do anything about them with their very limited time. Instead, the resource team should intervene in cases where we see that if nothing is done now, it will become messed up—not when it already has been messed up. (Principal)

Some teachers argued that there were other challenging students with difficulties but who were not as problematic and hard cases as the most extreme cases often involved in the resource team activities, which would be more realistic to work with-to keep them in the regular classroom and general education.

Deciding which students were best suited for resource team activity of course was not an easy judgment call, which in turn pointed to the necessity of dynamic goals and being prepared to handle cases that first proved to be too difficult during the intervention period or unsuitable to reconcile with an inclusive education. The goals had to gain approval with and be supported by the teachers so that they worked toward the same goals. In contrast to static goals, dynamic goals appeared to be an important strategy to gain acceptance among the teachers. This was not about abandoning the idea of inclusion but in an active way working and interacting to gaining approval for this intention through dialog with teachers and together investigating and considering the possibilities of inclusive education in every real case.

\section{Responsibility}

Responsibility transferring was another phenomenon that seemed to result in desynchronizing. Responsibility transferring means that actors disclaimed responsibility or had responsibility taken away for the target student's positive development. According to many teachers and some principals, a lot of teachers had an attitude and behavior, which expressed a desire for 
relief, that is, to transfer all responsibility to team members instead of sharing the responsibility with the team member and collaborating to promote the student's progress. According to the team members' accounts, the perspectives and attitudes varied, however, to some degree across different schools or teachers. "There are teachers who say, 'Please take him out!' But another teacher might ask, 'What do you think we should do? I can see there is a problem here.' And then we have a dialogue" (Team member). Some teachers were more focused on trying to help keep the target student in the regular classroom, whereas others were more focused on relief by removing the target student from the classroom. When the team members met the latter group of teachers, which they said that they mostly did, they experienced that effective collaboration was much more difficult to accomplish-whereas they were working with direct interventions with students and parents, consultation with these teachers did not work or take place at all.

Responsibility transferring involved making the teachers' role and work with the target student passive, with team members taking over the whole responsibility. This means that the team members themselves conducted most or all interventions. Thereby, the teachers did not become involved in the intervention work by consultation. Neither were other professionals from organizations or institutions beyond school involved. Because the responsibility of conducting the intervention work to such a large degree rested on the team members, at least two risks could be identified: (a) loss of effectiveness because the professionals around the target student were not synchronized and did not actively collaborate toward shared goals in the particular case, and (b) short-term effects, that is, a risk that good results would depend on the team members' presence at school, which means that when the resource team intervention period was over, there was an obvious risk that the target student returned to the problems or developed similar problems because no one else around the student continued to shoulder the processes that the resource team had initiated. Many teachers and some principals talked about this dependency on team member presence.

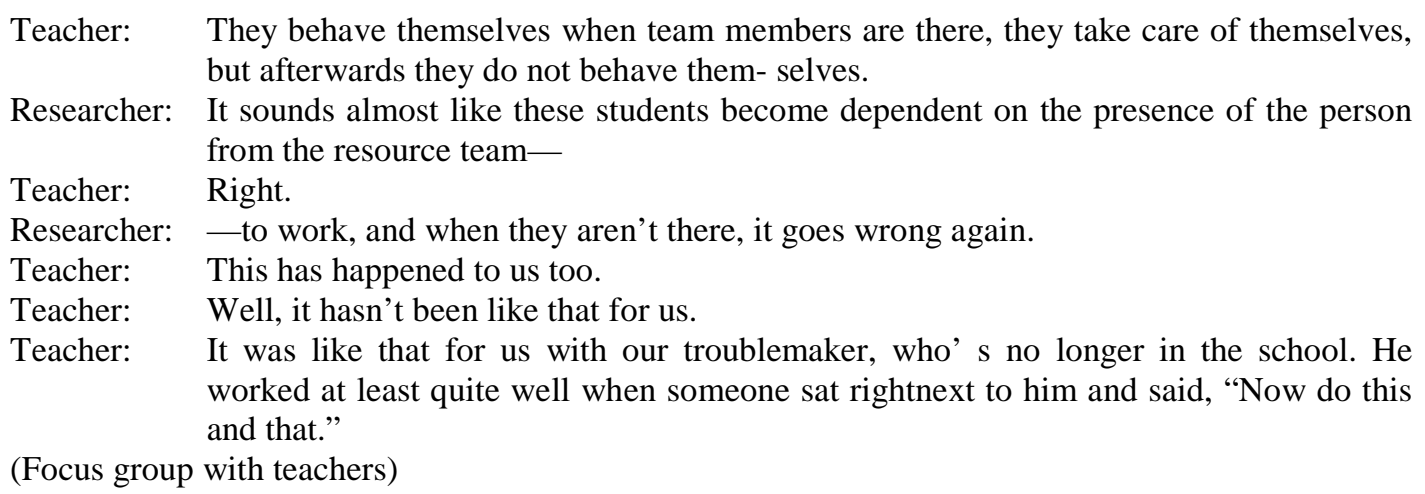

These experiences started off worries among teachers and principals about what would have happened when the resource team intervention period regarding the target student was over.

What happens afterwards, when the resource team- when they aren't there any more? Can you trust that new networks are in place, taking care of the problem? In other words, the issue is: What'll happen then? So that everything doesn't just collapse then. (Teacher)

Notice that the teacher still expressed responsibility transferring but in this case to future "new networks" instead of the resource team in the excerpt.

Responsibility sharing was a phenomenon that, according to the grounded theory, was necessary for synchronizing. Responsibility sharing means that team members as well as school personnel took responsibility for initiating processes that aimed to support and assist 
the student to develop in a positive direction. The project in other words was in these cases a shared project and not one person's job. One of the teachers who was satisfied with the collaboration and its outcomes expressed a clear involvement in the resource team process,

We [the teacher and the team member] had regular meetings, we've been able to see each other when the students have gone, and been able to sit down for a while every week to discuss the student, token economy and things like that, and how to organize the work.

Instead of making all the interventions by themselves, responsibility sharing means that the team members worked more actively as consultants to involve and assist the teachers in the intervention work. In addition, the team members involved trained professionals from other organizations or institutions outside the school. By consultation as well as active crosssector networking, together they all created conditions for maintaining the process of supporting the target student's positive development after the team members have finished their intervention period. Furthermore, responsibility sharing also means that the professionals shared responsibility with the target student and his or her parents as well. They were involved as active participants in the process (not as passive receivers). By working toward shared responsibility and full participation from all parts from the outset of the intervention period, the conditions for the development of appropriate expectations from all parts increased.

\section{Professional Cultures}

Counteracting professional cultures means that professionals and profes- sional cultures came into conflict with each other and more or less cancelled each other out. "Us and them" thinking had developed in which individual stuck together in their own group while looking at and judging the other group with suspicion and skepticism. The resource team and teachers had negative representations about each other and viewed their own professional culture as better and more competent.

It often happens that we kind of talk about "us" and "them." They [the resource team] represent one idea and we [the teachers] represent another idea about how we want things to be. We want to have good order in the classroom. We want a classroom situation that works. And I'm sure it will work if this student is not there (Teacher).

In the focus group with teachers, many attacked the resource group by labeling their members as incompetent, not knowing how the school worked, not understanding learning goals in different school subjects, and so on. "We don't expect someone who knows everything but someone who actually has an enormous competence in this stuff . . . It hasn't felt that he was better than us in the level-in the level of competence" (Teacher). In the focus group with the resource team, team members criticized teachers for not using evidence-based methods and not approaching hard-to-teach students in a competent way as well as being unwilling to replace non-constructive habits and strategies with constructive ones. They claimed that many teachers were not interested in listening to them because they just wanted to get relief by removing the target student from their classrooms.

Such negative social representations of each other appeared to counteract and undermine the motivation for collaboration across the professional cultural boundaries. They resulted in isolated and narrow-minded professional thinking and acting. They enacted professional selfdefense and protectionism instead of multiprofessional collaboration and consultation. Obscurity and lack of communication (teachers said that they were still not sure about the meaning of the resource team, and teachers as well as team members complained about poor communication from the other side and about team members' lack of basic knowledge about how things work in school) as well as lack of accessibility to collaboration as a result of lack of time (which team members and many teachers complained about) appeared to promote and maintain the problem of counteracting professional cultures. In addition, the manifestation of 
counteracting professional cultures seemed to motivate a further lack of communication and lack of accessibility to collaboration. Moreover, counteracting professional cultures could be linked to the change resistance of the school culture and team members' lack of legitimacy vis-à-vis the teachers.

Principal: But I think that this isn’t a new problem that here, the thing about people from outside coming in and trying to get some kind of legitimacy in the school.

Principal: It's not easy.

Principal: School people are a bit prickly to deal with. In some way however-

Researcher: What do you mean?

Principal: Well, about someone from outside coming in as an expert. That's something, I think, that-

Principal: The teachers play a waiting game.

Principal: - -we've had the attitude for a long time: "Does this person really know anything about these things?" (in a skeptical tone). And maybe this is the same in all professions, what do I know. I only have experience from school. Nevertheless, you can say that because it's difficult, it's also an important aspect. You can't just ignore it. If you don't deserve legitimacy, then it's all over.

(Focus group with principals)

Hence the school and teacher cultures appeared to have a strong tendency to categorize professionals from outside the school in terms of "them" or outgroup members and attribute negative stereotypes to them when these professionals came to the school. This pattern easily led to the development of counteracting professional cultures. The resources became more or less desynchronized in relation to school personnel.

In contrast, coordinating professional cultures means that the various professionals and professional cultures coordinated and were made available to each other to have active collaboration. By their distinct and specific competences they complemented and developed each other in their interaction and collaboration. The other group was not viewed as deficient or a threat, but as a valuable resource. There was an "us" thinking across the professional borders focusing on the shared project of promoting and supporting the positive development of the target student. Good integration between resource team and school personnel was created and resulted in a "team spirit." "We could communicate very well and worked together to improve the situation for the student in the school and we really complemented each other in this work" (Teacher). There was a striving for mutual understanding in which different perspectives and expertise were combined to create better opportunities for seeing and considering the whole student problem, to improve problem solving and to broaden the repertoire of interventions. A real multiprofessionalism had been developed. Consultation was not about team members knowing everything and transferring this knowledge to the teachers-an initial expectation among many teachers (who became disappointed because team members did not act in accordance with such expectations and were therefore defined as incompetent). Instead the team member functioned as a sounding board by actively listening, co-thinking, and giving the teacher opportunities for reflections. With regular consultation, the team members could offer teachers other perspectives and methods and together formulate how the teacher or teachers would work further on with the target student. There was a fruitful giving and taking in which the different competences actively contributed to the whole. In this way, the human resources became synchronized.

Unfortunately, according to the reports from teachers, principals, and team members, effective coordinating professional cultures seldom took place.

We haven't really — or I think that the teachers haven't understand that this is something that we have to solve together. Thus, the word "together" is in fact a key word that hasn't really been spread, 
but you [the teachers] think that someone from outside school should come and fix it. (Principal)

Nevertheless, in some instances, interaction patterns similar to coordinating professional cultures were reported, and often team members explained this in terms of teachers' openness and willingness to collaborate.

\section{Relations}

In the grounded theory developed here, relations refer primarily to those interaction patterns and relationships that took place not only between grown-ups (teachers, team members, parents, and so forth) and the target student but also between professionals (teachers, team members, principals, and so forth) and the parents of the target student. If the relationships and interaction patterns were aversive and negative, a desynchronizing of human resources seemed to occur (especially when we consider the target student and his or her parents as main human resources).

Aversive relations mean that the interaction pattern and relationship between the grownup and the student were perceived as unpleasant (aversive) by the student (and probably even by the grown-up) in which both parts had a negative attitude and approach to each other and primarily focused on the student's deficits and negative behavior, which in turn tended to reinforce and emphasize the aversions in the interaction (negative feedback, negative criticism, reproaches, punishment, anger, rejection, and so forth). According to some students, their teachers' negative attitudes and expectations of them demotivated them and turned into a self-fulfilling prophecy.

\footnotetext{
Student: They [the teachers] just thought, how can I put it, well, saw me as disruptive and stuff.

Researcher: They saw you as disruptive?

Student: Yeah.

Researcher: What do you think about that, that they saw you as disruptive?

Student: Well, so by then I didn’t think it was particularly fun to go to school.

(Interview with a student)
}

In aversive relations, conflicts often occurred and these were typically handled with destructive and hostile behavior (threat, coercion, anger, verbal aggression, power assertion, and so forth). In such processes, teachers and other grown-ups tended to use aversive methods and approaches vis-à-vis the target student. A negative spiral took place in which grown-ups and the student developed negative expectations of attitudes to and behavior toward each other. Desynchronizing had occurred. The relationships were negative and infected. The students in the study described histories of aversive relations with their teachers and how such relations counteracted their academic motivation and inspired them to behave "badly" or inappropriately in school. The students expressed a feeling of not being seen, liked, and understood by their teachers.

\footnotetext{
Researcher: When you were rowdy like that, what do you think caused that, during the time before you met Kim [the team member]?

Student: $\quad$ No one noticed me at school. No one understood me ... And when I was rowdy and stuff, it was perhaps a cry for help or stuff.

(Interview with a student)
}

Furthermore, parents reported how they repeatedly received negative messages from teachers about how bad or problematic their children were at school. "They just called at home and there were complaints all the time” (a parent). They never received any positive information about their children. Only negative. This in turn resulted in resistance from some of the parents, which counteracted effective collaboration between home and school. "Be- 
cause you thought, 'It can't just be Robin's fault. You opposed them right from the start. And it can still be like this. Because I know it isn't just Robin's fault” (Parent). One of the parents in the study also reported how this narrow-minded negative reporting from school undermined her self-esteem as a parent. "They often called me, and then you felt useless as a parent" (Parent). According to some of the parents, when as a parent you heard all the time from teachers that your child had done "bad things" or "doesn't do any work" and only negative things like that, then you developed a negative attitude to the dialog with teachers or school. They did not perceive this as a constructive starting point. In aversive relations, professionals viewed students and parents as "antagonists" or "opponents." School personnel who were primarily involved in aversive relations with marginalized students (and their parents) would inevitably remain desynchronized with them as well as with the team members who consciously strove to avoid and break aversive relationships and interaction patterns.

In contrast, positive relations led to enhanced synchronizing between adults and the target student, between professionals and parents, and between school personnel and resource team. It was about interaction patterns and relationships in which adults had a positive attitude and approach to the target student as well as to his or her parents, and which mainly (but not only) focused on the target student's strengths and positive behavior. Students and parents were viewed as "partners" or "co-players." The professionals worked consciously with developing positive and supporting relationships with the target student and his or her parents. They mainly used positive, constructive, and pedagogical methods and approaches (e.g., trying to understand the student and his or her situation, actively listening, positive feedback, bounding, mediating confidence in student's capacity, constructive criticism, positive reinforcement, and motivating interviewing). The professionals tried to handle conflicts that occurred with constructive strategies, that is, everyone listening to each other and together trying to find solutions that all sides are happy with. The students and parents in this study reported experiences of positive relations with the team members, which in turn resulted in trust and motivation to collaborate with them, and as they saw as a clear contrast to their relations with the teachers.

\footnotetext{
Student: I quickly got some confidence in John [a team member].

Researcher: How did that come about?

Student: I don't know, I felt that he was a good person and that I could talk to him about a lot of stuff.

Researcher: How did you recognize that he was a good person?

Student: $\quad$ He helped me a lot, talked to me-I was able to talk about serious things with him ... And he cares.

Researcher: And he cares? What do you mean by that, that he cares?

Student: $\quad$ Well, he supports me. He doesn't give up so easily.

(Interview with a student)
}

Some of the parents associated the positive effects of the resource team on their children's academic and social achievements with the positive and supportive relationships between team members and their children.

They [team members] are responsive and nice, and explain everything to Jonathan, and don't just say, "Now you have to do that and that, now you have to do this and this," but they might explain, "Now you have to do this because . . . ," and stuff like that, which the teachers didn't do before. (Parent)

One of the parents told me that the main reason why the collaboration worked so well and why her son made many positive achievements was "because of this trust that Sonny [her son] and I have in Kathy [a team member]." The parents also perceived that this positive and 
supportive approach differentiated team members from teachers as well as explained why they and their children had confidence in team members but not in teachers. Hence, positive relationships and interaction patterns between professionals and students as well as their parents synchronized professionals, parents, and target student in their work of enhancing the target student's development and achievement.

\section{Discussion}

Multiprofessional collaboration has a lot of advantages in making a more effective problemsolving and intervention-generating process compared to isolated individual achievements (e.g., Brown \& Bolen, 2008; Cook et al., 2001; Poulton \& West, 1999; Toseland et al., 1986), and my findings confirm this by pointing to advantages when such collaboration functions well. Nevertheless, my findings also confirm other research (e.g., Robinson, 2002; SlonskiFowler \& Truscott, 2004; Spratt et al., 2006) that indicates that problems and pitfalls easily might arise when teachers and other professionals interact with each other and with students and their parents. By analyzing teachers, principals, nonschool situated resource team members (trained social workers and special educators), challenging students, and parents' reported experiences and representations about their interactions and collaborations, I have developed a grounded theory of collaborative synchronizing in relation to challenging students in school. The current study contributes to the already existing literature a set of concepts generated from the analysis of the participants' perspectives on collaboration.

According to the grounded theory in the current study, (a) goal setting, (b) responsibility, (c) professional cultures, and (d) relations are core elements in how well human resources are synchronized to conduct a movement toward the target student's healthy and positive development and outcomes. It indicates that human resource synchronizing (a process that includes and coordinates different people so that they integrate and interact together in a way that results in the positive development of the target student) is associated with dynamic goal setting, responsibility sharing, coordinating professional cultures, and positive relations, whereas resource desynchronizing (a process that counteracts integrating and coordinating of resources) is linked to static goal setting, responsibility transferring, counteracting professional cultures, and aversive relations.

Involving teachers, principals, parents, and the student him- or herself in the ongoing process of formulating and decision making of goals appears to be a highly relevant strategy for special educators, school counselors, trained social workers, school psychologists, or other professionals who are assigned to change a negative and unhealthy pattern linked to a challenging or at-risk student. In fact, the grounded theory in the current study actually indicates that goal dissonance was a core process in desynchronizing. All the significant people around the target student, including the student, should be treated as members of a team with the shared project of making life and life opportunities better for the student.

When many people are involved in a shared project, there is always a risk of what social psychologists call free riding (i.e., contributing less to a collective task when one believes that other members will compensate for this lack of effort but then taking advantage of the outcomes or achievements of the group or social collective), social loafing (i.e., the reduction of individual effort when people work in groups compared to when they work alone), and diffusion of responsibility (i.e., tendency of individual to assume that others in a group or a social collective will take responsibility; Forsyth, 2006, pp. 231-234, 297-304; Hogg \& Vaughan, 2008, pp. 278-283, 544). The grounded theory in the current study points to the pitfall of responsibility transferring in which teachers seek relief instead of collaboration and so transfer all responsibility to the resource team members, who in turn take over the student. This leads to resource desynchronizing, consultation loss, diffuse and passive teacher role, and delayed and less effective interventions. This can also be associated with research showing (a) 
insufficient teacher involvement or participation in the process (Meyers et al., 1996; Robinson, 2002; Slonski-Fowler \& Truscott, 2004), as well as (b) teachers' perceptions of having limited skills and preparation for working with challenging students (Drame \& Frattura, 2011).

Another pitfall that the grounded theory of collaborative synchronizing in relation to challenging students highlights is counteracting professional cultures, which means that professionals and professional cultures are being put into conflict with each other and counteract each other. Whereas the process of counteracting professional cultures identified in the study promoted cohesion and belongingness within the resource team as well as within teacher groups, it blocked or undermined professional collaboration between team members and school staff. Here an "us and them" thinking had been generated in which each professional group had negative social representations or stereotypes about each other. The problems of professional boundaries, mistrust, and out- group devaluation in multiprofessional collaboration in school settings have also been shown in other studies (Meyers et al., 1996; Robinson, 2002; Slonski-Fowler \& Truscott, 2004; Spratt et al., 2006).

Nevertheless and in contrast to responsibility transferring and counter-acting professional cultures, my grounded theory indicates that responsibility sharing and coordinating professional cultures are core elements in the productive process of resource synchronizing. This means that the work is viewed as a shared project in which everyone takes responsibility, that teachers have a significant and active role, that all parties see each others as valuable resources, are well-disposed to mutual understanding, considering multiple perspectives, and are available for each other to make an active and effective collaboration possible. There is a "team spirit" and an "us" thinking across the professional borders focusing on the shared project of promoting and supporting the positive development of the target student. Nonteaching or nonschool professionals have to be prepared to and consciously cope with the discrepancies of professional cultures and the change resistance of the school culture to avoid counteracting professional cultures and instead efficiently coordinate and synchronize the different professional competences to maximize the intervention effectiveness.

Another main theme in the grounded theory of the current study is the significance of relations. Whereas positive relations are associated with resource synchronizing, aversive relations are associated with resource desynchronizing. It is especially clear that aversive relations desynchronize professionals with target student and parents. Whereas team members in my study strive to establish and maintain positive relations with target students as well as with parents, in many cases the relations between teachers and target students as well as between school and home appear to be more aversive, typically focusing on negative issues while using aversive strategies and interaction patterns. According to the students and parents' reports in this study, this difference has a significant influence on their attitudes, motivation, and involvement, and explains why they listen to and trust the team members and engage in the interactions with them, in contrast to how they approached the teachers and the school settings in the past.

Many studies have shown that positive (warm and supportive) teacher-student relationships are linked to students' academic achievement, social adjustment, and mental health, peer relations, (for reviews, see Pianta, 1999, 2006), and are especially beneficial to "at-risk" students (e.g., Hamre \& Pianta, 2005, 2006; Meehan, Hughes, \& Cavell, 2003) and students growing up in socially disadvantaged neighborhoods (Gregory \& Ripski, 2008; Rey, Smith, Yoon, Somers, \& Barnett, 2007). Nevertheless, interactions between good-intended teachers and challenging students might vary depending on student and teacher characteristics, selfdefinitions, beliefs, and the influence of support staff, as Kennedy's (2011) in-depth study illustrated. Furthermore, the professionals' positive relations with parents as a core element of resource synchronizing in the current grounded theory can be linked to meta-analyses, which 
indicate that parental involvement positively influences academic achievement of students growing up in socially disadvantaged neighborhoods (Jeynes, 2003, 2005). Nevertheless, the findings in my study illustrate some pitfalls in the relation work between school and home as well as between teacher and student, and hence help to make professionals conscious about them to avoid them and focus on positive and supportive relationships instead.

Finally, the findings also indicated the practice of "doing student problem cases" among teachers and principals in schools, that is, talking about and dealing with problems in everyday school or classroom life in terms of particular "student cases," which produced or manifested a dominant discourse of deficient students. Identified problems were understood and explained as deficiencies or pathologies within the students who had been addressed as "problem cases." In addition, the resource team members displayed a rather ambivalent approach to this discourse. On one hand, they wanted to challenge how teachers and principals talked about and understood the problems with these students by applying a socio-ecological perspective. On the other hand, in their communication with teachers and principals and by their taking over of the "student problem cases," the team members actively participated in the dominant discourse of deficient students. The very talk of "challenging student" in school can easily lead to "within-student" explanations of the problem (cf. the concept of "blaming the victim"). Nevertheless, from a socio-ecological perspective, "challenging students" in school are understood as an ecological phenomenon that is established and maintained as a result of the complex interplay between individual and contextual variables. Thus "challenging students" have to be understood across individual, family, peer, school, and community contexts. Because the dominant discourse of deficient students produces biomedical and individual-psychological interventions and silences contextual interventions, this very discourse counteracts the process of resource synchronizing, and therefore has to be exposed and challenged.

\section{Limitations and Generalizability}

Several limitations to the grounded theory and the conclusions drawn in this study should be noted. First, it is important to recognize that this is a study with a small and nonprobability sample. For example, other parents, students, or teachers involved in the resource team project might have reported other things. Moreover, the sample from a particular practice in a particular area of Sweden might or might not be similar to the context in which and people with whom the readers primarily work. Second, the grounded theory of multiprofessional collaboration and resource synchronizing is built on analyses of experiences, representations, and conceptions that team members, teachers, principals, parents, and students expressed in their conversations in this study. It is not built on direct observations of collaboration and its effects. Thus it is important to recognize that the links were not identified by statistical methods of observational data of multiprofessional collaboration, but identified by in-depth analysis of the participants' narratives about their multiprofessional collaboration.

Third, this study did not gather data on students' academic and social achievements in the form of grades, school subject tests, established behavioral check lists, and psychological tests to statistically investigate the effects of the resource team intervention project-only narrative reports from target students, parents, team members, teachers, and principals. Fourth, the rather homogeneous group of "challenging students" (they have all been reported to have a high degree of similar academic and behavioral problems) described as "student cases" in the resource team activity, has hindered my analysis of how different types of "student problems" might affect the human resource synchronizing (e.g., behavioral problems vs. academic problems). Fifth, school differences due to the school context (disadvantage vs. mix district) between considering attitudes and approaches vis-à-vis the resource team did not emerge when I analyzed the data. Perhaps a study with a larger sample, including a lot more schools, might 
have identified such differences. Thus, the small sample of schools and the rather homogeneous student sample in the reported "student cases" have hindered me from more fully analyzing student challenge and school context variations as possible factors.

Instead of statistical generalization built on the logic of mathematics, in qualitative research generalization has been discussed as an interpretation work in terms of, for example, generalization through conceptualization (Glaser, 1978, 1998), generalization through recognition of patterns, and generalization through context similarity, in which the reader, not the researcher, judges the generalizability (Larsson, 2009). According to Glaser (2003), a generated grounded theory is "not accurate facts and not description. It is just straightforward conceptualization integrated into theory - a set of plausible, grounded hypotheses" (p. 14) that has to be tested by further research, which is always the case in inductive and abductive investigations. Moreover, in line with a constructivist position (Charmaz, 2006), the grounded theory in the current study should be viewed as an interpretative portrayal of patterns and connections rather than an exact picture of simple linear reasoning. Interpretative research, like this study, is concerned around how the social world is experienced and understood by a particular group or set of participants, and to uncover how people think and feel about the world or a particular practice and make sense of their lives or social interactions from their particular vantage points (King \& Horrocks, 2010).

\section{Conclusions and Implications}

In accordance with the logic of extrapolation (Patton, 2002), the grounded theory presented in this study can be used (a) to analyze multiprofessional collaboration and consultation in school settings and (b) as a basis for discussion in local evaluation and developmental work of multiprofessional collaboration, student-teacher relations, school-home collaboration, and school consultation. The dichotomized ideal types, human resource synchronizing and human resource desynchronizing, and their subprocesses of goal setting, responsibility, professional cultures, and relations, offer "looking glasses" or analytic tools to practitioners and researchers as well.

At least two main conclusions of the grounded theory in the current study could be made. First, to create good conditions for effective collaboration and consultation, an inclusive participation has to be obtained ("getting everyone on the train") in which teachers, principals, other involved professionals, parents, and students are invited into the processes of formulating and making decisions about goals, actively participate in problem-solving processes, and are perceived and valued as significant resources who can contribute by their different knowledge and experiences with a more comprehensive view and effective changes and interventions. Developing positive relations with students and parents (and thus avoiding aversive relations) is an important strategy to motivate and involve them in the work of enhancing the students' development and achievement. All the parties are concerned with the target student's positive development. A desynchronizing process that passivates and devaluates the target student, the parents, or the teachers has to be counteracted. Therefore, involved individuals have to avoid goal dissonance and responsibility transferring (attributing responsibility to others but not to oneself). High resource synchronizing requires that all parts participate and are focused on how they can contribute to a positive change of the student's situation.

Second, there has to be an acceptance of multiprofessionalism as a superior ideology. To do a more effective job by surmounting professional barriers and taking the advantage of professional differences, there has to be an acceptance of the multiplicity of professionals and professional cultures. Multiprofessional collaboration cannot be imposed by force. Being preoccupied with defending one's own profession, combined with an inability or unwillingness to consider other professional perspectives, results in counteracting professional cultures. 
Negative social representations of other professional groups make the professionals draw attention to and exaggerate other professionals' deficiencies, whereas their strengths and merits are belittled, ignored, or rationalized away. If actors seriously see the benefits of multiprofessionalism, then they also have to seriously accept and affirm multiprofessionalism as a superior ideology instead of ending up in professional territorial thinking and acting. Disagreements and diversity of opinions, perspectives, and methods between different professionals are then not perceived as threats but as starting points for significant and fruitful discussions aiming to expand the field of view and together develop comprehensive and effective interventions.

\section{References}

Banfield, P., \& Kay, R. (2008). Introduction to human resource management. Oxford, UK: Oxford University Press.

Bennett-Emslie, G. M., \& McIntosh, J. (1995). Promoting collaboration in the primary care team-the role of the practice meeting. Journal of Interprofessional Care, 9, 251-256.

Blumer, H. (1969). Symbolic interactionism: Perspective and method. Berkeley: University of California Press.

Brown, M. B., \& Bolen, L. M. (2008). The school-based health center as a resource for prevention and health promotion. Psychology in the Schools, 45, 28-38.

Charmaz, K. (2006). Constructing grounded theory. London, UK: SAGE. structionism and the grounded theory method. In J. A. Holstein \& J. F. Gubrium (Eds.), Handbook of constructionist research (pp. 397-412). New York, NY: Guilford Press.

Charmaz, K. (2009). Shifting the grounds: Constructivist grounded theory methods. In J. M. Morse, P. N. Stern, J. Corbin, B. Bowers, K. Charmaz \& A. E. Clarke (Eds.), Developing grounded theory: The second generation (pp. 127-154). Walnut Creek, CA: Left Coast Press.

Charon, J. M. (2007). Symbolic interactionism: An introduction, an interpretation, an integration (9th ed.). Upper Saddle River, NJ: Prentice Hall.

Cook, G., Gerrish, K., \& Clarke, C. (2001). Decision-making in teams: Issues arising from two UK evaluations. Journal of Interprofessional Care, 15, 141-151.

Deaux, K., \& Philogène, G. (Eds.). (2001). Representations of the social: Bridging theoretical traditions. Malden, MA: Blackwell.

Drame, E. R., \& Frattura, E. (2011). A charter school's journey toward serving all learners: A case study. Urban Education, 46, 55-75.

Erevelles, N. (2006). Deconstructing differences: Doing disability studies in multi- cultural educational contexts. In S. Danforth \& S. Gabel (Eds.), Vital questions facing disability studies in education (pp. 363-378). New York, NY: Peter Lang.

Farrell, P. T., Howes, A. J., Jimerson, S. R., \& Davies, S. M. (2009). Promoting inclu- sive practice in schools: A challenging role for school psychologists. In T. B. Gutkin \& C. R. Reynolds (Eds.), The handbook of school psychology (4th ed., pp. 821- 839). Hoboken, NJ: John Wiley.

Fiske, S. T., \& Taylor, S. E. (2008). Social cognition: From brain to culture. Boston, MA: McGrawHill.

Forsyth, D. R. (2006). Group dynamics (4th ed.). Belmont, CA: Thomson. Desmond, M. S., Perrin, J. M., \& Murphy, J. M. (2000). Utility of psychosocial screening in a school-based health center. Journal of School

Health, 70, 292-299.

TGelasericBl. Sens(it878).. San Francisco, CA: Sociology Press.

Glaser, B. G. (1998). Doing grounded theory. San Francisco, CA: Sociology Press.

Glaser, B. G. (2003). The grounded theory perspective II: Description's remodeling of grounded theory methodology. San Francisco, CA: Sociology Press.

Glaser, B. G., \& Strauss, A. L. (1967). The discovery of grounded theory. New York, NY: Aldine de Gruyter.

Gregory, A., \& Ripski, M. B. (2008). Adolescent trust in teachers: Implications for behavior in the high school classroom. School Psychology Review, 37, 337-353.

Gutkin, T. B. (2009). Ecological school psychology: A personal opinion and a plea for change. In T. 
B. Gutkin \& C. R. Reynolds (Eds.), The handbook of school psychology (4th ed., pp. 463-496). Hoboken, NJ: John Wiley.

Hamre, B. K., \& Pianta, R. C. (2005). Can instructional and emotional support in the first-grade classroom make a difference for children at risk of school failure? Child Development, 76, 949-967.

Hamre, B. K., \& Pianta, R. C. (2006). Student-Teacher relationships. In G. G. Bear \& K. M. Minke (Eds.), Children's needs III: Development, prevention, and intervention (pp. 59-71). Bethesda, MD: National Association of School Psychologists.

Hjörne, E., \& Säljö, R. (2004). The pupil welfare team as a discourse community: Accounting for school problems. Linguistics and Education, 15, 321-238.

Hjörne, E., \& Säljö, R. (2008). Att platsa i en skola för alla: Elevhälsa och förhandling om normalitet i den svenska skolan [To qualify in a school for all: Student health and negotiating about normality in the Swedish school]. Stockholm, Sweden: Norstedts Akademiska Förlag.

Hogg, M. A., \& Vaughan, G. M. (2008). Social psychology (5th ed.). Harlow, Essex, UK: Pearson.

Hylander, I. (2003). Towards a grounded theory of the conceptual change process in consultee-centered consultation. Journal of Educational and Psychological Consultation, 14, 263-280.

Jeynes, W. H. (2003). A meta-analysis: The effects of parental involvement on minority children's academic achievement. Education and Urban Society, 35, 202-218.

Jeynes, W. H. (2005). A meta-analysis of the relation of parental involvement to urban elementary school student academic achievement. Urban Education, 40, 237-269.

Kaiser, B., \& Rasminsky, J. S. (2009). Challenging behavior in elementary and middle school. Upper Saddle River, NJ: Pearson.

Kennedy, B. L. (2011). The importance of student and teacher interactions for disaffected middle school students: A grounded theory study of community day schools. Urban Education, 46, 433.

King, N., \& Horrocks, C. (2010). Interviews in qualitative research. London, UK: SAGE.

Klingner, J. K., \& Harry, B. (2006). The special education referral and decision-making process for English language learners: Child study team meetings and placement conferences. Teachers College Record, 108, 2247-2281.

Knotek, S. (2003). Bias in problem solving and the social process of student study teams: A qualitative investigation. Journal of Special Education, 37, 2-14.

Kovaleski, J. F., Gickling, E. E., Morrow, H., \& Swank, P. R. (1999). High versus low implementation of instructional support teams: A case for maintaining program fidelity. Remedial and Special Education, 20, 170-183.

Larsson, S. (2009). A pluralist view of generalization in qualitative research. International Journal of Research \& Method in Education, 32, 25-38.

Meehan, B. T., Hughes, J. N., \& Cavell, T. A. (2003). Teacher-student relationships as compensatory resources for aggressive children. Child Development, 74, 1145-1157.

Meyers, A. B., Valentino, C. T., Meyers, J., Boretti, M., \& Brent, D. (1996). Implementing preferral intervention teams as an approach to school-based consultation in an urban school system. Journal of Educational and Psychological Consultation, 7, 119-149.

Meyers, J., Truscott, S. D., Meyers, A. B., Varjas, K., \& Smith Collins, A. (2008). Qualitative and mixed-methods designs in consultation research. In W. P. Erchul \& S. M. Sheridan (Eds.), Handbook of research in school consultation (pp. 89-114). New York, NY: Lawrence Erlbaum.

Mills, M., Bonner, A., \& Francis, K. (2006). Adopting a constructivist approach to grounded theory: Implications for research design. International Journal of Nursing Practice, 12, 8-13.

Mishna, F., Saini, M., \& Solomon, S. (2009). Ongoing and online: Children and youth's perceptions of bullying. Children and Youth Services Review, 31, 1222-1228.

Morgan, D. L. (1998). The focus group guidebook. Thousand Oaks, CA: SAGE.

Moscovici, S. (2001). Social representations: Explorations in social psychology. New York: New York University Press.

Patton, M. Q. (2002). Qualitative research \& evaluation methods (3rd ed.). Thousand Oaks, CA: SAGE.

Patrikakou, E. N., \& Weissberg, R. P. (2000). Parents' perceptions of teacher outreach and parent involvement in children's education. Journal of Prevention \& Intervention in the Community, 20, 103-119. 
Pianta, R. C. (1999). Enhancing relationships between children and teachers. Washington, DC: American Psychological Association.

Pianta, R. C. (2006). Classroom management and relationships between children and teachers: Implications for research and practice. In C. M. Evertson \& C. S. Weinstein (Eds.), Handbook of classroom management: Research, practice, and contemporary issues (pp. 685-709). Mahwah, NJ: Lawrence Erlbaum.

Poulton, B. C., \& West, M. A. (1999). The determinants of effectiveness in primary health care teams. Journal of Interprofessional Care, 13, 7-18.

Rey, R. B., Smith, A. L., Yoon, J., Somers, C., \& Barnett, D. (2007). Relationships between teachers and urban African American children. School Psychology Inter- national, 28, 346-364.

Robinson, F. (2002). Lessons learned from implementing problem-solving teams in urban high schools. Journal of Educational and Psychological Consultation, 13, 185-217.

Shaw, R. S., Kelly, D. P., Joost, J. C., \& Parker-Fisher, S. J. (1995). School-linked and school-based health services: A renewed call for collaboration between school psychologists and medical professionals. Psychology in the School, 32, 190-201.

Slonski-Fowler, K. E., \& Truscott, S. D. (2004). General education teachers' perceptions of the prereferral intervention team process. Journal of Educational and Psychological Consultation, 15, 1-39.

Spratt, J., Shucksmith, J., Philip, K., \& Watson, C. (2006). Interprofessional support of mental wellbeing in schools: A Bourdieuan perspective. Journal of Interprofessional Care, 20, 391-402.

Sun, J., \& Stewart, D. (2007). Development of population-based resilience measures in the primary school setting. Health Education, 107, 575-599. 